\title{
Moisture determination for food quality assessment
}

\author{
Rolle F. ${ }^{1, a}$, Beltramino G. ${ }^{1}$, Fernicola V. ${ }^{1}$, Sega M. ${ }^{1}$, Verdoja A. ${ }^{1}$ \\ ${ }^{1}$ INRiM-Istituto Nazionale di Ricerca Metrologica, Strada delle Cacce 91, 10135 Torino, Italy
}

\begin{abstract}
Résumé. Dans ce travail on décrit les activités préliminaires effectuées à l'INRiM visant à développer des procédés métrologiquement valides pour la détermination de la teneur en eau dans différentes matrices alimentaires (feuilles de thé, fructose, poudre de lait pour les préparations pour nourrissons). La teneur en humidité est un paramètre fondamental affectant les conditions de stockage des denrées alimentaires, la sécurité et la qualité sensorielle des aliments transformés. Des échantillons d'aliments ont été analisés en utilisant deux techniques électrochimiques sélectives pour l'eau, le titrage coulométrique Karl Fischer (cKF), équipé d'un four de séchage, et l'analyse appelée «Evolved Water Vapour» (EWV). Ces techniques permettent la détermination de la teneur en eau dans des échantillons solides et peuvent être très utiles en tant que le pré-traitement des échantillons est considérablement réduit par rapport à la $\mathrm{cKF}$ liquide. Les paramètres de fonctionnement les plus importantes ont été examinés et une attention particulière a été consacrée à la mise en place de la traçabilité métrologique des résultats de mesure et à l'évaluation de l'incertitude de mesure.
\end{abstract}

\section{Introduction}

The Istituto Nazionale di Ricerca Metrologica (INRiM) is developing the metrology infrastructure for providing traceability to moisture in materials. The activity is carried out in the framework of the European Joint Research Project EMRP SIB64 METefnet Metrology for Moisture in Materials with several other EU National Metrology Institutes. [1] The present work deals with the development of metrologically-sound procedures for the determination of the water content of selected food samples, by using two electrochemical methods, namely oven drying-coulometric Karl Fischer (cKF) titration and Evolved Water Vapour analysis (EWV). The chosen matrices are simple sugars (e.g. fructose), tea leaves, and infant formula milk powder. The determination of water in sugars can be useful for assessing the properties and the biological origin of some foodstuffs (e.g. honey). On the other hand, the storage conditions of infant formulas and tea products, which are largely used worldwide, are paramount for consumer safety. In addition, many economical aspects depend on moisture measurements, e.g. food drying is an energyintensive process which requires optimization to save energy. Finally, the products sold beyond international borders must meet the requirements of the receiving Country and many products are usually sold on a dry matter basis [2].

The standardised procedures for moisture measurement in solids prescribe that the moisture determination is carried out by measuring the mass loss of a sample, by weighing it before and after the drying process. These methods, named Loss on Drying (LoD) techniques, are not water selective but might extract also other volatiles and the sample may still contain residual water after drying $[1,3]$. In this framework, the use of chemical techniques selective for water is fundamental to confirm the LoD results. In addition, a rigorous measurement uncertainty analysis is in many cases unavailable. For these reasons, there is a need of implementing measurement methods which can assure full metrological traceability to SI.

The preliminary results obtained at INRiM are presented in this work.

\section{Experimental}

The first part of the work was devoted to the optimisation of the operating parameters of $\mathrm{CKF}$ and EWV and to the establishment of metrological traceability for the measurement results of these techniques. Secondly, some food matrices were investigated.

The optimisation of the operating parameters for $\mathrm{cKF}$ concerned:

- duration of the analysis;

- sample heating temperature;

- stirring rate;

- drift value;

- ambient parameters (e.g. relative humidity and temperature);

- repeatability.

\footnotetext{
a Corresponding author: f.rolle@inrim.it
} 
It was highlighted that the instrumental drift is a fundamental parameter and it affects the repeatability of the analyses.

For EWV, the optimised parameters were:

- efficiency of the desiccant system;

- stability of the background during the analyses;

- sample position in the oven;

- sample heating temperature;

- repeatability;

- sample pre-treatment.

Metrological traceability was established for cKF and EWV by using certified mass standards for the determination of the sample masses and suitable reference materials to calibrate the electrochemical instruments (Hydranal ${ }^{\circledR}$ Water Standard KF Oven 5.55 $\%$, Merck Oven Standard 1.07\%).

Some details on the different techniques are reported.

\subsection{Coulometric Karl Fischer titration}

The cKF titration is a chemical direct method that uses a reaction selective for water, based on the oxidation of sulphur dioxide $\left(\mathrm{SO}_{2}\right)$ :

$$
3 \mathrm{Z}+\mathrm{ROH}+\mathrm{SO}_{2}+\mathrm{I}_{2}+\mathrm{H}_{2} \mathrm{O} \rightarrow 3 \mathrm{ZH}^{+}+\mathrm{ROSO}_{3}{ }^{-}+2 \mathrm{I}^{-}
$$

where $\mathrm{Z}$ is a base and $\mathrm{ROH}$ is an alcohol (usually methanol).

The consumption of iodine $\left(\mathrm{I}_{2}\right)$, which is stoichiometrically equivalent to the water present in the sample, is measured: $I_{2}$ is produced by the generating electrode from iodide $\left(\mathrm{I}^{-}\right)$and the end point of the reaction is determined by a second electrode. The mass of water present in the sample is calculated from the amount of electric current (Coulomb) used for $\mathrm{I}_{2}$ production.

$$
2 \mathrm{I}^{-} \square \mathrm{I}_{2}+2 \mathrm{e}^{-} \square \mathrm{H}_{2} \mathrm{O}
$$

The apparatus used at INRiM is a coulometric Karl Fischer titrator $c 30$ from Mettler-Toledo, which can determine the water content in the range between $2 \mathrm{ppm}$ and $5 \%$. The instrument is equipped with a Stromboli oven in which solid samples are heated and the volatile compounds are carried into the KF titration cell for selective water determination by a flux of dried air (or pure nitrogen).

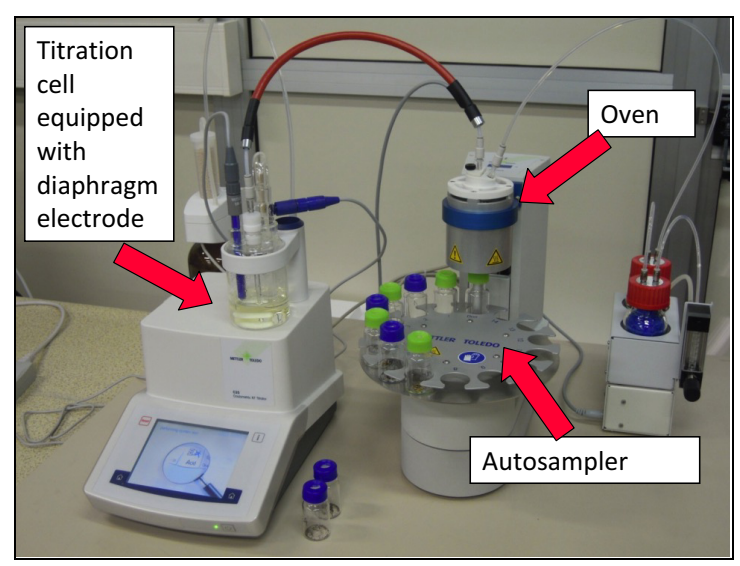

Figure 1. INRiM cKF $c 30$ apparatus equipped with the Stromboli drying oven

\subsection{Evolved Water Vapour analysis}

The Evolved Water Vapour (EWV) analysis was carried out at INRiM by using a commercial instrument, WDS 400 from Sartorius, having a moisture measurement range between $1 \mathrm{ppm}$ and $40 \%$ of water. It is equipped with a phosphorous pentoxide $\left(\mathrm{P}_{2} \mathrm{O}_{5}\right)$-coated sensor and a coulometric detector. The instrument can differentiate among surface, capillary and crystallisation water. The solid samples are placed into a drying oven and a flux of dried air carries the released water vapour on the sensor. Here $\mathrm{P}_{2} \mathrm{O}_{5}$ absorbs the water vapour, due to its high hygroscopy, and phosphoric acid is formed. The reaction product is then electrolysed to yield hydrogen $\left(\mathrm{H}_{2}\right)$ and oxygen $\left(\mathrm{O}_{2}\right)$ and regenerating $\mathrm{P}_{2} \mathrm{O}_{5}$.

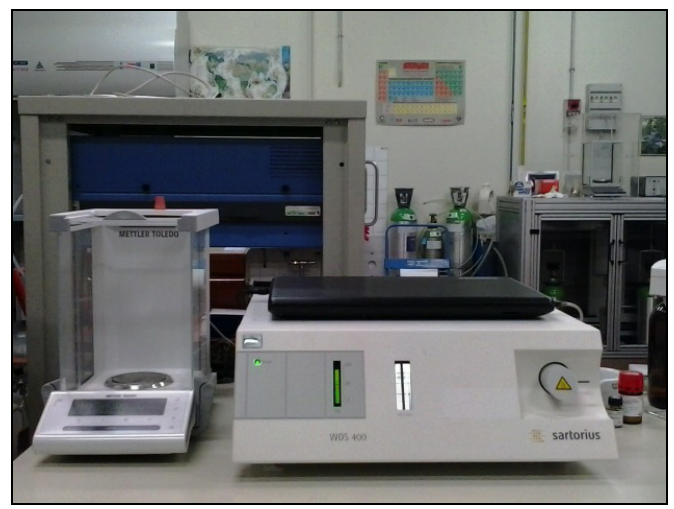

Figure 2 INRiM WDS 400 from Sartorius equipped with a balance for precision weighing of the samples to be analysed

\section{Results and discussion}

In this work the preliminary results obtained for some food matrices with $\mathrm{cKF}$ are presented.

Figure 3 reports the results obtained for the analysis of fructose with cKF. Two temperatures were considered for the analysis of this matrix, $105{ }^{\circ} \mathrm{C}$, which is the temperature commonly used in the LoD techniques, and $95{ }^{\circ} \mathrm{C}$. The results are in good agreement and, for this reason, a temperature lower than $105^{\circ} \mathrm{C}$ can be preferred for the analysis, as melting of the sugar can be avoided.

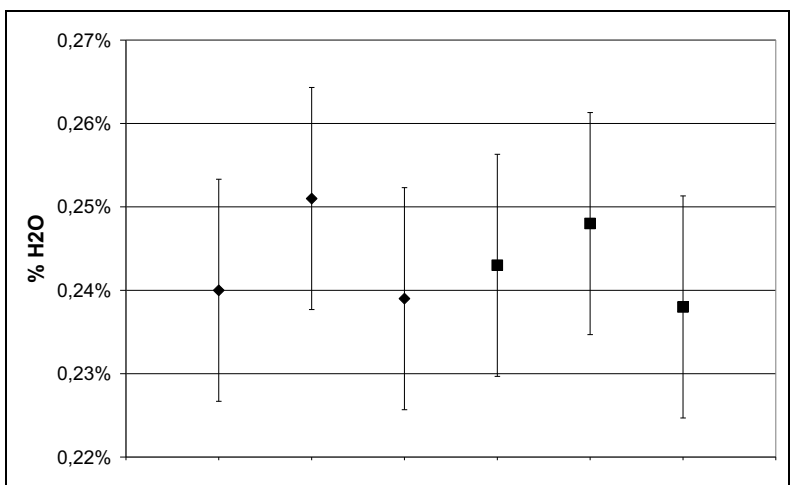


Figure 3. Results obtained for fructose analyses by $\mathrm{cKF}$ at 95 ${ }^{\circ} \mathrm{C}(\bullet)$, and $105{ }^{\circ} \mathrm{C}(\bullet)$. The expanded uncertainties are the standard deviations of repeated measurements multiplied by $k=2$

The measured water content for fructose was around 0.24-0.25\%, hence in agreement with the results found in literature $(<0.5 \%$ of water).

As for infant formula milk powder, typical moisture content ranges between 2 and $7 \%$ of water, while for lactose the moisture content is $4-6 \%$. From preliminary measurements carried out at $105^{\circ} \mathrm{C}$ by cKF, we obtained an average value of $5.8 \%$ of water, with an expanded uncertainty of $0.2 \%(k=2)$, in samples on infant formula purchased in a local market in Torino, Italy. Usually moisture measurements for these kinds of matrices are carried out by pre-treating the samples in suitable organic solvents: the goal is the development of metrologically traceable procedures for the quantification of the water content directly in the solid matrix, reducing the use of toxic solvents and the uncertainty coming from the pretreatment step.

The sample heating temperature plays a very important role in the amount of water determined in the samples. Concerning tea leaves, the water content was observed to increase with the drying temperature. In figure 4 this trend is shown for cKF analysis. Good repeatability was obtained for measurements at 120-140 ${ }^{\circ} \mathrm{C}$, which lowers with increasing temperature.

On one side, these results could suggest that the temperature of $120{ }^{\circ} \mathrm{C}$ is not enough for a quantitative extraction of the water present in the tea leaves. On the other hand, increasing too much the temperature might lead to excessive release of water for degradation processes of the tea constituents, thus generating additional water.

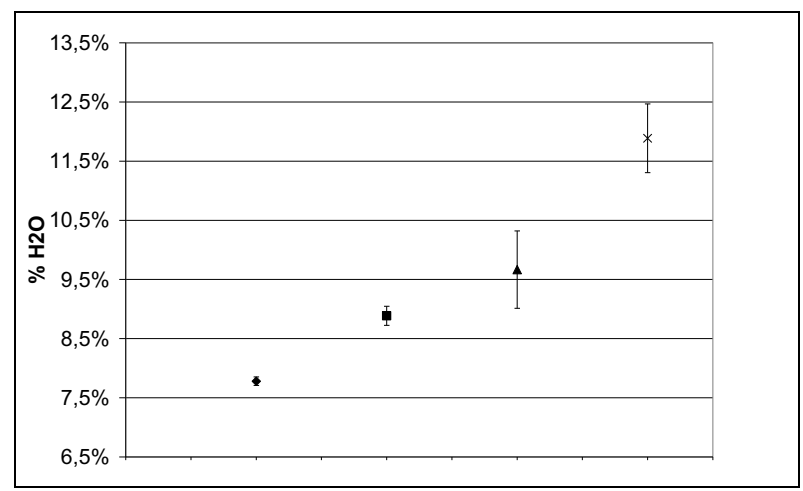

Figure 4. Results obtained for tea leaves analysed by $\mathrm{cKF}$ at $120^{\circ} \mathrm{C}(\diamond), 140{ }^{\circ} \mathrm{C}(\boldsymbol{\bullet}), 160{ }^{\circ} \mathrm{C}(\boldsymbol{\Delta})$, and $180{ }^{\circ} \mathrm{C}(\mathrm{X})$. The expanded uncertainties are the standard deviations of repeated measurements multiplied by $k=2$

\section{Conclusions}

The present paper describes the preliminary work carried out at INRiM to set up metrologically-sound procedures for the determination of water content in different types of food samples. Two electrochemical methods, namely coulometric Karl Fischer (cKF) titration and Evolved Water Vapour analysis (EWV) were used. The coulometric methods that are based on chemical reactions selective for water can be considered as promising techniques for moisture measurements in solid materials to confirm the results obtained by the classical LoD techniques.

A particular attention was paid in assuring metrological traceability to the measurement results by using calibrated mass standards for the weighing procedures and certified reference materials to calibrate cKF and EWV analysers. As for the uncertainty evaluation, the work is ongoing, taking into account all the relevant sources, e.g. the instrumental repeatability, the contributions from the sample weighing process and from the procedure used for the calibration of the instruments.

Additional work is foreseen for determining the most suitable heating temperature for tea samples and for optimising the analytical method for infant formulas milk powder.

\section{Acknowledgements}

The present work was carried out within the European Joint Research Project "SIB64 METefnet - Metrology for Moisture in Materials". The project is funded by European Metrology Research Programme (EMRP), implemented by European Association of National Metrology Institutes (EURAMET).

\section{References}

1. http//www.metef.net/

2. H.-D. Isengard, Food Chemistry 106, (2008), 1393 1398

3. D. C. Hinz, J. Pharm. Biomed. Anal, 43, 2, (2007), 779-783 